\title{
Interview expectancies: awareness of potential biases influences behaviour in interviewees
} Nicole M. Adams-Quackenbush, Robert Horselenberg, Josephine Hubert,
Aldert Vrij \& Peter van Koppen

To cite this article: Nicole M. Adams-Quackenbush, Robert Horselenberg, Josephine Hubert, Aldert Vrij \& Peter van Koppen (2019) Interview expectancies: awareness of potential biases influences behaviour in interviewees, Psychiatry, Psychology and Law, 26:1, 150-166, DOI: 10.1080/13218719.2018.1485522

To link to this article: https://doi.org/10.1080/13218719.2018.1485522

(c) 2019 The Author(s). Published by Informa UK Limited, trading as Taylor \& Francis Group

曲 Published online: 22 Jan 2019.

Submit your article to this journal

Џll Article views: 2733

Q View related articles $\longleftarrow$

View Crossmark data $\asymp$ 


\title{
D OPEN ACCESS Check for updates
}

\section{Interview expectancies: awareness of potential biases influences behaviour in interviewees}

\author{
Nicole M. Adams-Quackenbush ${ }^{\mathrm{a}, \mathrm{c} *}$ (D), Robert Horselenberg ${ }^{\mathrm{a}}$, Josephine Hubert ${ }^{\mathrm{b}}$, \\ Aldert Vrij ${ }^{\mathrm{c}}$ and Peter van Koppen ${ }^{\mathrm{d}}$ \\ ${ }^{a}$ Department of Criminal Law \& Criminology, Maastricht University, Maastricht, Netherlands; \\ ${ }^{\mathrm{b}}$ Department of Clinical Psychological Science, Maastricht University, Maastricht, Netherlands; \\ ${ }^{\mathrm{c}}$ Department of Psychology, University of Portsmouth, Portsmouth, United Kingdom; ${ }^{\mathrm{d} D e p a r t m e n t}$ \\ of Criminal Law \& Criminology, VU University Amsterdam, Amsterdam, Netherlands
}

\begin{abstract}
Expectancy effects are known to influence behaviour so that what is expected appears to be true. In this study, expectancy was induced using (fabricated) information about honesty and specific group membership. Targets were tested in a non-accusatory interview environment using neutral and information-gathering questions. It was hypothesized that those exposed to the negative information (the expectancy) would demonstrate behaviour consistent with an increased cognitive load, and evidence was found to support this prediction. Due to the investigative nature of the information-gathering questions, it was also expected that the targets exposed to the expectancy would exhibit more of these behaviours in the investigative portion of the interview. Some behaviour was found to support this prediction (i.e. shorter responses and increased speech disturbances); however, indicators of performance altering load were not observed during this phase of the interview. These findings support the hypothesis that expectancy effects can noticeably alter interviewee behaviour.
\end{abstract}

Keywords: investigative interviews; expectancy effects; cognitive load; interviewee behaviour; stereotype activation; information-gathering; truth-tellers.

Imagine a situation where someone in a position of authority is asking you questions about a recent event. The atmosphere is collegial, and the questions are not difficult or strongly worded. You may feel a bit nervous simply due to the difference in social status. Perhaps you are trying hard to recall a detail to impress this person, which only adds more pressure to the situation. Imagine that during one of your responses you suddenly get the impression that this person is suspicious of your answers. This person has not said anything to imply suspicion, yet you feel as though something has changed between you. Was it something you said? Did your body language send the wrong signal? Perhaps it is neither, and your internalized insecurities have planted this doubt in your mind. How do you recover? What do you do? Now imagine a similar exchange with a police officer who is investigating a crime.

* Correspondence: Nicole M. Adams-Quackenbush, Maastricht University Faculty of Law, Department of Criminal Law \& Criminology, P.O. Box 616, 6200 MD, Maastricht, Limburg, Netherlands. Email: Nicole.adams@maastrichtuniversity.nl 
This scenario outlines a common interaction that occurs within a unique environment. A police investigative interview is generally a high-stakes, stressful and cognitively taxing situation for everyone involved. Investigative interviews are wrought with factors that can directly affect the outcome (Gudjonsson, 2003), as well as influence the behaviour of both interviewer and interviewee (Kassin et al., 2009; Leo, 2009). In the exchange above, the dominant factor is an expectancy effect that originates in the person answering the questions. Given the prevalence of expectancy effects within most human interactions, this topic has started to receive more attention in forensic contexts such as criminal investigations (Hill, Memon, \& McGeorge, 2008), decision-making in judicial professionals (Porter \& Ten Brinke, 2009) and accusatory investigative interviews (Kassin, 2005; Kassin, Goldstein, \& Savitsky, 2003).

Within the framework of the investigative interview, expectancy effects are often studied as a by-product of confirmation bias held by police officers or other judicial players (Narchet, Meissner, \& Russano, 2011; Powell, Hughes-Scholes, \& Sharman, 2012; Rassin, Eerland, \& Kuijpers, 2010). However, little research has been conducted in the area of the investigative interview to examine how expectancy effects may arise internally in the interviewee based on the interviewee's perception of the situation. The present study is an attempt to apply aspects of social psychological theory on expectancy effects to the study of interviewee behaviour. In order to investigate the effects of expectancy, the focus is placed on the verbal and non-verbal behaviour of truth-telling interviewees. Of specific interest are behaviours that are conventionally associated with cognitive load but that are also (erroneously) cited as signs of suspicion or evasiveness. The implications of the impact of expectancy effects on investigative interviews are then discussed in the context of the existing literature.

\section{Expectancy effects as stereotype activation}

When expectancy effects occur within a dyadic or polyadic interaction, it has been repeatedly demonstrated that the behaviour of the perceiver (the one who holds the expectation or false belief) can influence the behaviour of the target (the one whose behaviour is being perceived). ${ }^{1}$ In turn, the target's behaviour ultimately confirms the expectation of the perceiver, thus giving the perceiver evidence that his or her false belief is true (Merton, 1948; Snyder \& Haugen, 1994; Snyder \& Stukas, 1999). Darley and Fazio's (1980) model of the expectancy confirmation process illustrates how expectancy effects can be introduced into a normal sequence of social interaction. In their model, Darley and Fazio posit that expectancy effects are introduced into an interaction when the perceiver forms or holds expectancy about the target. The interaction is then subsequently influenced by both the target's and the perceiver's behaviour based on that expectancy. However, expectancy effects can also occur as an internal event for a single person based on his or her own beliefs and expectations. In the larger expectancy confirmation process model, an internally derived expectancy effect occurs at the phase described as the target interpreting the perceiver's behaviour (Darley \& Fazio, 1980, p. 872). In this case, the expectancy effect occurs in the absence of any behavioural cues from the perceiver; instead, the expectancy arises from the target's knowledge about beliefs that may be held by the perceiver. This phenomenon is most commonly seen in the presence of self-perceptions (Fazio, Effrein, \& Falender, 1981) or because of an activated group stereotype (Wheeler \& Petty, 2001).

When an expectancy is activated based on a group stereotype, the target is in a situational

${ }^{1}$ Within an interaction, the target and perceiver roles frequently alternate. For the purpose of this paper, the perceiver is always the interviewer and the target is always the interviewee. Additionally, perceiver/ interviewer and target/interviewee are used interchangeably throughout the paper, depending on the context. 
predicament where he or she is at risk of conforming to negative beliefs about a group to which he or she belongs, regardless of whether he or she believes the stereotype or not (Bargh, Chen, \& Burrows, 1996; Steele \& Aronson, 1995). Subsequent research has identified three main conditions necessary for this type of expectancy to occur. The first condition, stereotype awareness, requires that the target is aware of the negative belief (Schmader, Major, \& Gramzow, 2001). The second condition, domain identification, requires that the target cares about doing well in the specific situation (Rosenthal, Crisp, \& Suen, 2007). The third condition, task difficulty, requires that the task has some level of difficulty for the target (Keller, 2007). When all three of these conditions are present, the effects of the stereotype have been shown to impede a target's performance (Schmader \& Johns, 2003), carry over into unrelated situations (Fazio et al., 1981) and inhibit working memory (Schmader, Johns, \& Forbes, 2008).

Although stereotyping as an expectancy effect is well documented in social psychological and educational research (see Pennington, Heim, Levy, \& Larkin, 2016), only recently has it been investigated within the legal context. Najdowski (2012) investigated racially motivated stereotypes to demonstrate that persons of African American heritage are significantly more likely to report feeling the effects of stereotyping than persons of White European heritage when in contact with law-enforcement officers. Moreover, these effects increase when questions are asked regarding a recent crime in the area. Najdowski hypothesizes that the effects of stereotyping in these encounters could influence African Americans to behave in ways that may indicate suspicion to a law-enforcement officer (e.g. increased nervousness, odd body language and decreased eye contact). In such cases, the target's awareness of the stereotypes concerning his or her group and criminal activity becomes activated when he or she is approached by a law-enforcement officer.
The effects of stereotyping in relation to expectancy are not solely limited to group membership based on race; research has demonstrated that these effects also occur based on age (Lamont, Swift, \& Abrams, 2015), sex (Leslie, Cimpian, Meyer, \& Freeland, 2015) and disability (Silverman \& Cohen, 2014). Therefore, it may be possible to induce this effect using negative beliefs about a variety of group membership types. For example, an expectancy response could be activated when a false belief concerns an individual's likelihood to commit a crime based on low socioeconomic status, low education level, gang membership, substance use and/or criminal history. However, mitigating stereotype activation for these groups would be extremely challenging in a law-enforcement context. A police officer may encounter many people who belong to one or more of these criminally stereotyped groups. Moreover, the false belief does not have to be explicitly stated to create the expectancy effect and alter the target's behaviour (Bargh et al., 1996). That is, if the false beliefs are implicitly present within the interaction, or unknowingly primed in the interviewee, stereotype activation may occur despite the officer's best efforts to put the interviewee at ease.

\section{Expectancy effects and behaviour}

Comprehending behaviour in the context of the situation is important, because behaviour is what the perceiver observes and uses to confirm her or his beliefs and inform her or his consequent conduct towards the target. Once the beliefs have been confirmed, the perceiver may then use this information when encountering other members of the target's group, thus perpetuating the stereotype and the expectancy. Most investigations of expectancy effects rely on self-report measures completed by the target to determine their potential presence. Other studies also use measures such as heart rate, skin conductance and EEG outputs to understand the physiological symptoms 
involved (Pennington, Heim, Levy, \& Larkin, 2016). However, few studies use observational methods to investigate the verbal and non-verbal behaviours of targets who are experiencing expectancy effects. Najdowski (2012) examined how expectancy effects in the form of a stereotype may translate into non-verbal behaviour by videotaping the interactions between targets and a law-enforcement officer. Najdowski investigated nine types of non-verbal conduct and found that two behaviours differentiated the targets by racial groups: African Americans appeared significantly more nervous during the interaction and used fewer manipulations (self-touching) and illustrators (gestures). The appearance of nervousness in Najdowski's study could be deemed a subjective measure that varies by perceiver; however, the reduced amount of movement is consistent with the findings of Vrij and Mann (2001). While observing videotaped interview sessions between a murder suspect and a police interviewer, the researchers noted that the suspect did not fidget much during the interview and remained unnaturally still when asked difficult or case-specific questions. The researchers concluded that the suspect may have exhibited a high level of control over his body movements to mask when he was being deceptive. However, these conclusions cannot explain why similar behaviour was seen in non-criminal, truth-telling targets during Najdowski's (2012) study.

In a subsequent study, Mann, Vrij, and Bull (2002) examined the videotaped behaviour of 16 police suspects during investigative interviews. They coded both verbal and nonverbal behaviours: gaze aversion, blink frequency, head movements, hand/arm movements, pauses in speech and speech disturbances (stutters, trips and verbal crutches). They found that the suspects blinked less and paused more often during speech when lying, and concluded that these behaviours are consistent with increased cognitive load in the suspect - that is, the act of lying, elements of the environment and the interrogative situation combined to tax the mental resources of the suspects in such a way that it affected their verbal and non-verbal behaviour (Gombos, 2006). This means that as the suspects experienced increased demands on their working memory, they had less control over their verbal and non-verbal behaviour (Engle, 2002). The combined findings of Najdowski (2012) and Mann et al. suggest that during an investigative interview there are increased cognitive demands that can be observed through interviewee behaviour, regardless of statement veracity.

\section{Implications of expectancy effects in the interview room}

The aforementioned research findings demonstrate the impact of expectancy effects on cognition, inhibited learning, motivation and performance using various types of group membership (e.g. age, sex, race, socio-economic status, etc.). In summary, expectancy effects tax the cognitive resources of the person experiencing it in a way that impairs performance. Thus, an interviewee experiencing an expectancy effect, and the resulting increased cognitive load, may have fewer mental resources available to adequately identify and deal with the demands of the interview. There is also evidence that the impacts of expectancy effects can linger and negatively influence performance in a broad range of situations that are unrelated to the nature of the expectancy (Inzlicht, Tullett, \& Legault, 2011). Croizet et al. (2004) demonstrated that individuals experiencing expectancy as stereotype show a decrease in performance due to increased mental load. This finding is especially significant in relation to investigative interviewing conditions, wherein the interviewee's cognitive resources may already be undermined by the perceived severity of the situation. Thus, if expectancy effects are also present, a suspect's behaviour may be affected, meaning that his or her ability to fully comprehend the interviewer's questions and appreciate the 
implications of his or her responses to those questions may be impaired (Berggren, Richards, Taylor, \& Derakshan, 2013).

Understanding expectancy effects as an inducer of cognitive load during investigative interviews is important for two reasons: i) increased load can undermine performance such as memory recall (Barrouillet, Bernardin, Portrat, Vergauwe, \& Camos, 2007) and question comprehension (Wallen, Plass, \& Brunken, 2005), and ii) some of the behaviour indicative of increased load can be misinterpreted by police interviewers as suspicious behaviour. For example, a suspect who appears nervous to an interviewer and who also has difficulty remembering timelines, details and events could be deemed to be uncooperative and evasive. A suspect who appears distracted, avoids eye contact, exhibits increased speech disturbances and seems overtly nervous may also be considered shifty or guilty. Mann, Vrij, and Bull (2004) demonstrated that police officers most often use decreased eye gaze $(78 \%)$ and increased body movements $(31 \%)$ to determine veracity in a suspect. Judging deception in this manner is problematic, however, because these behaviours are faint and unreliable (De Paulo et al., 2003), even though they are often used as signs of deception across many cultures and countries (Global Research Deception Team, 2006). Mann, Vrij, Fisher, and Robinson (2008) suggest that attending to non-verbal behaviour may also strengthen the tendency for police officers to see deception.

If a police officer is accustomed to using non-verbal behaviour to determine deception and evasiveness, it may be enough to prompt him or her to believe that a suspect is lying or guilty. When this occurs, previous research has demonstrated that in a confession-driven investigative interview scenario, the interviewing officer may then increase interrogative pressure and engage in more coercive tactics (Kassin et al., 2003,2007, 2009). Although the extant literature has encouraged law-enforcement agencies to move away from coercive interview tactics (Kassin et al., 2009), the application of interrogative pressure to obtain a confession is still common practice in many countries (Areh, Walsh, \& Bull, 2016; Kassin et al., 2007). Given the high-pressure, highstakes nature of investigative interviews, it is easy to imagine how cognitive load can have an adverse effect on interviewees' performance. Some countries have abandoned confession-driven interviews in favour of information-gathering interviews (e.g. the PEACE model; see Clarke \& Milne, 2001). The goal of information-gathering interviews is to obtain as much information as possible from all interviewees (including suspects) without seeking an admission of guilt and without using intimidation, bluffs or promises. Although this type of interview is only used in a few countries - e.g. the United Kingdom (UK), Norway and Australia - it is widely regarded as an effective and more ethical type of investigative interviewing technique (Shawyer, Milne, \& Bull, 2009). However, many of the factors identified as problematic in the confession-driven interview have not been tested with the information-gathering interview; this means it is still unknown as to which phenomena are specific to one type of interview and which occur as an outcome of all types of investigative interview.

\section{The present study}

The effects of feeling as though you are being targeted or judged based on group membership is relevant to all human interactions, including encounters with law-enforcement officers. The aim of the present study is to investigate expectancy effects on behaviour when expectancies have only been implied through information about the participant's group membership. Given that most research on investigative interviews uses accusatory or confession-driven interview techniques to study interviewee behaviour (see Kassin et al., 2009; Meissner, Redlich, Bhatt, \& Brandon, 2012), little is known about expectancy 
confirmation effects in non-accusatory environments while using information-gathering techniques. Additionally, inducing expectancy effects as a stereotype has not been investigated in a forensic setting using non-raciallymotivated false beliefs. To address these gaps in the literature, negative information about group membership and honesty was used to induce an expectancy effect because of its performance-impairing properties, as well as its ability to generalize to a variety of situations.

A 2 (expectancy vs control) $\times 2$ (neutral vs information-gathering questions) mixed design was employed to test the hypotheses. In line with previous research on expectancy effects and stereotype activation, it was expected that awareness of negative beliefs about group membership would influence the target's performance during the interview that is, targets exposed to the expectancy would exhibit behaviour indicative of increased cognitive demands (decreased body movements, decreased blink rate, increased eye closure, increased gaze aversion, shorter response length and increased speech disturbances) during both types of interview questions. Additionally, it was predicted that targets exposed to the expectancy would exhibit more of these behaviours in the information-gathering phase of the interview due to the activation of the stereotype prime just prior to the beginning of the information-gathering questions, and the more investigative nature during this phase of the interview.

\section{Method}

\section{Participants}

A total of 52 targets ( 37 females and 15 males) were recruited from a university in the Netherlands based on a current grade point average (GPA) of less than 7.9. The targets were all recruited based on GPA to ensure that the negative information was specific to the domain of the academic environment. The targets volunteered to complete the study under the pretence that the researchers were investigating the relationship between GPA and sensory perception (i.e. a taste-testing task). Negative information about their grade range was fabricated and introduced to the targets as a belief through a series of fictitious scientific studies. The targets in the expectancy group were given information that people with a GPA of lower than 8 are more likely to lie and cheat on tasks in order to be successful. All targets were tested individually and were naive to the true purpose of the study.

One female participant was excluded from the analysis because she reported that her GPA had improved in the time between recruitment and participation $\left(n=51 ; M_{\text {Age }}=21.14\right.$ years, $S D=1.84)$. Most targets were undergraduate students $(72.6 \%)$ in their first $(21.9 \%)$ or third (23.5\%) year of study. Targets recruited via the faculty participant pool received one research participation credit as an incentive. No incentive was offered to those recruited outside of the faculty participant pool.

\section{Measures and materials}

A blind taste-testing task was used to provide a task that would not betray the true nature of the study. The task also allowed for a situation wherein the participant would be left alone and could choose to complete the task honestly or just lift the covers on the juice bottles in order to obtain the answers. To set up the task, six different brands of apple juice were purchased at a local supermarket. The juice was poured into six identical 500-ml plastic bottles with paper labels showing the brand name. For the blind portion of the test, opaque paper covers were slid over each bottle so that the brand name was no longer visible.

The study took place in a small room equipped with a table for the tasting task, a computer to record the questionnaire responses and present the stimulus material and an HD video camcorder to film the participant and record the interview. The digital video was saved on a data card and transferred to an encrypted external hard drive after every two or three testing sessions for later editing and 
Table 1. Definitions of the verbal and non-verbal behaviours coded in the study, the corresponding Krippendorff's alpha $(\alpha)$ for interrater reliability and the predicted direction of the differences in behaviour for the targets exposed to the expectancy.

\begin{tabular}{|c|c|c|c|}
\hline Behaviour & Operational definition & $\alpha$ & $\begin{array}{l}\text { Predicted direction } \\
\text { of change }\end{array}$ \\
\hline Response length & $\begin{array}{l}\text { The duration for which the target speaks during the } \\
\text { video clip }\end{array}$ & .99 & $<$ \\
\hline Blink frequency & $\begin{array}{l}\text { Brief closure of both eyes lasting less that one second; } \\
\text { includes blink flurries and rapid blinking }\end{array}$ & .92 & $<$ \\
\hline Eye closure & $\begin{array}{l}\text { Lids completely drawn together for more than one } \\
\text { second; no sclera, iris or pupils are visible }\end{array}$ & .92 & $>$ \\
\hline Manipulations & $\begin{array}{l}\text { Scratching, rubbing, tapping, grooming or touching the } \\
\text { self; includes crossed arms and clasped hands }\end{array}$ & .94 & $<$ \\
\hline Illustrators & $\begin{array}{l}\text { Gestures used to accentuate speech; includes shoulder } \\
\text { shrugs, head nods and shakes while speaking }\end{array}$ & .97 & $<$ \\
\hline Smile & $\begin{array}{l}\text { Corners of the mouth turned up to form a pleased, } \\
\text { friendly or kind facial expression; can be open or } \\
\text { closed mouth with teeth exposed or not }\end{array}$ & .89 & $<$ \\
\hline Laugh & $\begin{array}{l}\text { Spontaneous sounds associated with amusement or } \\
\text { nervousness }\end{array}$ & .99 & $<$ \\
\hline Gaze aversion & $\begin{array}{l}\text { The frequency with which the target breaks eye con- } \\
\text { tact with interviewer }\end{array}$ & .97 & $>$ \\
\hline $\begin{array}{l}\text { Serious facial } \\
\text { expression }\end{array}$ & $\begin{array}{l}\text { Intense or semi-flat affect; only coded if it occurs for } \\
\text { the duration of the video clip }\end{array}$ & .99 & $>$ \\
\hline $\begin{array}{l}\text { Speech } \\
\quad \text { disturbances }\end{array}$ & $\begin{array}{l}\text { Inarticulate sounds made throughout a statement that } \\
\text { include 'aahs', 'umm', etc. or elongation of vowels; } \\
\text { includes periods of silence lasting two seconds or } \\
\text { more; can occur at the end of a statement or } \\
\text { mid-statement }\end{array}$ & .93 & $>$ \\
\hline
\end{tabular}

analysis. Pre-interview, the targets completed a demographic questionnaire that captured their gender, age, year of study, GPA, current employment status and job title. As a manipulation check, targets provided self-report ratings of mood and self-confidence on a scale from 1 (extremely negative mood, extremely low selfconfidence) to 10 (extremely positive mood, extremely high self-confidence). This step was included to determine whether or not purposeful behaviours (countermeasures) or nervous behaviours could account for, or had an influence on, any of the outcome behaviours. The behaviours coded in this study were specifically chosen because they are reliable indicators of increased cognitive load. Other behaviours (i.e. smiling, laughing and serious affect) were coded as indicators of demeanour during questioning (see Table 1 for a complete list of behaviours).

Post-interview, the targets were asked to indicate from a checklist any symptoms of anxiety they may have experienced during the interview (see the supplemental material). They were also asked to select any behavioural countermeasures that they may have purposefully employed during the interview in order to appear honest and truthful to the interviewer (see the supplemental material). They then rated their mood and self-confidence again on scales from 1 to 10. Finally, the targets rated each of the interview questions on a scale from 1 (extremely nonaccusatory) to 10 (extremely accusatory). 
Table 2. The neutral and information-gathering questions asked during the interview.

Neutral questions

1. What did you like about the juice taste-testing task?

2. What did you think about the flavour of the juices we chose?

3 . What brand did you like the most?

4. What brand was easiest for you to recognize?

5. How often do you usually drink apple juice?

Information-gathering questions

1. Describe to me in detail what you did while I was out of the room.

2. How long did it take you to complete the task?

3. How many times did you sample each juice?

4. Did you think about lifting the coverings to look at the labels while I was out of the room?

5. Have you spoken with other students who have already completed this task?

\section{Stimulus and procedure}

The study was conducted by a research assistant who was blind to the condition and the main hypotheses. All participants were tested individually, and the research assistant used a script to ensure consistency for each participant. The research assistant was instructed to act in a friendly but professional manner throughout the course of the study. A review of the video recordings by the primary investigator showed that the research assistant was consistent with each participant and that there were no deviations from the study script.

Prior to taking part the participants provided partial informed consent, as the true nature of the study was concealed. Exactly what portions of participation would be videotaped was vaguely worded in order to obscure the fact the participants would be secretly videotaped the entire time. Once they had been equally and randomly assigned to either the expectancy group $(n=26)$ or the control group $(n=25)$, they completed the demographics survey and rated their self-confidence and current mood.

Next, the participants in the expectancy condition received a fabricated report about people with a GPA of less than 8 being more likely to lie and cheat to succeed at tasks. There was also fabricated information about the extremely low probability of someone with a GPA of less than 8 scoring $100 \%$ on any sensory perception task. This information was used to prime the participants in the expectancy group for an expectancy effect during the information-gathering stage of the study. The participants in the control group read general information about advertising and blind taste-testing. The cover stories were presented in sections, and after each section there were multiple choice questions designed to ensure that the participant attended to, and understood, the information.

The participants in both groups then received verbal instructions about the taste-test task. This task used six different brands of apple juice. The containers were uncovered and the participant was asked to taste each and memorize the brand. The research assistant then asked the participant to turn away, putting covers over the juice containers and shuffling their order. The participant was then asked to taste the juice again and identify each brand by taste alone. Each participant made her or his choice by marking the letter on the covering to the corresponding brand on an answer sheet. During this part, the research assistant left the room under the pretence of needing to retrieve the study materials. Meanwhile, the camcorder was recording the participant to verify later whether she or he lifted the covers to get a good score or not. A review of all tapes revealed that $100 \%$ of the participants self-elected into an honest condition, as no one cheated on the task.

After three minutes, the research assistant returned and prepared the room for the 
interview by positioning the participant in front of the camera and pretending to turn the video camera on (it was already recording). Each participant was asked five neutral questions about the task (Table 2) in order to establish baseline behaviour in the interview environment. The research assistant then pretended to score the participants' taste-test results. Regardless of group, each participant was told that she or he had scored perfectly, which should be impossible based on her or his GPA (in fact, no one scored perfectly on the task). The research assistant then claimed that she needed to ask some additional questions in order to make sure that the participant's data could be used. Five informationgathering questions were then asked (Table 2). The order of neutral and information-gathering questions was not counterbalanced to mimic the natural flow of an investigative interview, which generally moves from person-oriented questions to case-oriented questions.

Once the interview was completed, the video camera was turned off and the selfreport questionnaires were administered to capture the participants' ratings of nervousness and interview behaviours during the second set of questions (information-gathering), their perception of all the interview questions, a second self-confidence and current mood rating and their thoughts on the true nature of the study. In the final step, the participants received full written and verbal disclosure about the study. They were informed that they had been secretly taped during the taste-testing task, and consent for the use of their video in the study was obtained. The participants were also assured that their GPA did not indicate their inability to perform sensory tasks nor their likelihood to cheat or lie. They then watched a short humorous video to lift and possibly improve their mood in the event that it may have worsened during the study.

\section{Coding and intercoder agreement}

Each participant's video was edited into 10 clips that only included the participant's response to each question (51 participants $\times$ 10 clips for each video $=510$ video clips). Each clip was edited to start exactly when the interviewer finished talking and end just before the interviewer asked the next question. An event sampling technique was used to code the videos, with the duration of the video clip determining a single event. To control for variations in the duration of each video clip, all behavioural frequencies were standardized by dividing the counts by the duration of the video clip.

Three student interns who were blind to condition and hypotheses coded the video clips. These coders were first given training for one month that was designed to help them identify the target behaviours (see Table 1), and they were not permitted to analyse the study materials until they had achieved a preliminary interrater agreement of $80 \%$ on practice materials. The behaviours were recorded by counting the frequency of occurrences within the clip. Intercoder agreement was determined by having at least two coders score $30 \%$ of the same video clips, which were randomly selected from the sample. Krippendorff's alpha $(\alpha$, Hayes \& Krippendorff, 2007) was calculated for each of the behaviours, which generated an individual behaviour agreement (see Table 1). Overall agreement was also calculated, $\alpha=.986, \mathrm{CI}$ $=[.978, .990]$, which indicates an extremely high level of reliability. Acceptable K-alpha parameters were set at a minimum of $\alpha=.85$ for all behaviours. This could be interpreted as a conservative limit; however, an $\alpha=.80$ is regarded as 'good reliability'.

\section{Results}

\section{Preliminary analyses}

During the end-of-study questionnaire, the participants were asked if they had figured out the true nature of the study in order to determine whether or not this may have influenced their behaviours. No participant reported knowing what the study was really about, and all data 
are therefore usable. Analyses were first conducted to determine if there are differences between groups for self-reported mood. Differences were tested for between the expectancy group and the control group on self-confidence, anxiety and purposeful interview behaviours. A 2 (group) $\times 2$ (time) mixed-design analysis of variance (ANOVA) was conducted which demonstrates that the mood ratings do not differ between the first self-report at Time 1 and the second rating at Time $2\left(M_{1}=7.49, S D=1.06 ; M_{2}=7.49\right.$, $S D=0.96), F(1,49)=0.35, p=.556, \eta^{2}=$ .01. Furthermore, the expectancy group $\left(M_{\text {Expectancy }}=7.65, S D=0.89\right)$ does not differ from the control group $\left(M_{\text {Control }}=7.32\right.$, $S D=1.22)$ for overall rating of mood, $F(1$, $49)=2.68, p=.11, \eta^{2}=.05$. The analysis also demonstrates that the ratings of self-confidence remained stable from Time 1 to Time 2 $\left(M_{1}=7.08, \quad S D=1.14 ; \quad M_{2}=7.17\right.$, $S D=1.01), F(1,49)=0.40, p=.531, \eta^{2}=$ .01. Moreover, the expectancy group $\left(M_{\text {Expectancy }}=7.34, S D=1.29\right)$ does not differ from the control group $\left(M_{\text {Control }}=6.90\right.$, $S D=0.79)$ for overall reports of self-confidence, $F(1,49)=2.40, p=.128, \eta^{2}=.05$.

When participants were asked if they purposefully tried to appear more truthful by using any specific behaviour during the interview, $70 \%$ of the sample indicated that they used at least one of the listed tactics (see the supplemental materials), with the most common tactics reported as pausing to collect their thoughts $(31.4 \%)$ and maintaining open body language $(31.4 \%)$. The targets did not report having purposefully employed the behaviours of focus in the present study; therefore, the results in the main analysis were not influenced by the target's interview countermeasures. Furthermore, the most common symptoms of nervousness reported were stuttering or tripping over words $(23.5 \%)$, difficulty thinking $(17.6 \%)$ and feelings of defensiveness (17.6\%). An independent samples $t$-test shows that the targets in the control group $\left(M_{\text {Control }}=1.52, S D=1.36\right)$ reported more symptoms of nervousness than the targets in the expectancy group ( $M_{\text {Expectancy }}$ $=0.58, S D=0.94), t(49)=2.87, p=.006, d$ $=0.80,95 \%$ CI $[0.28,1.59]$. However, the control targets reported only one symptom on average, which is not indicative of experiencing enough anxiety to influence the behaviours of interest.

The participants were also asked to rate the interview questions on a scale of 1 (not accusatory) to 10 (extremely accusatory) for both the neutral and the information-gathering phases of the interview. Although there is a difference in the ratings for the two types of question (neutral versus information-gathering), no single question is rated as overtly accusatory. Overall, the participants rated the information-gathering questions as more accusatory than the neutral questions, $t(50)$ $=-9.75, p=.000, d=1.46,95 \% \mathrm{CI}[-3.43$, $-2.26]$; however, the mean scores for both types of question do not exceed the mid-point on the rating scale $\left(M_{\text {Neutral }}=1.80\right.$, $\left.S D=1.50 ; M_{\text {Info-gathering }}=4.65, S D=2.36\right)$. The question ratings were examined to see whether or not they differ by target group. There are no significant differences in scoring the neutral questions between groups, $t(49)=$ $-0.018, p=.99\left(M_{\text {Control }}=1.80, S D=1.38\right.$; $\left.M_{\text {Expectancy }}=1.81, S D=1.62\right)$. There are also no differences between groups when scoring the information-gathering questions, $t(49)=$ $-0.372, p=.71\left(M_{\text {Control }}=4.52, S D=2.20\right.$; $\left.M_{\text {Expectancy }}=4.77, S D=2.54\right)$.

\section{Main analysis}

There is some deviation from normality in many of the dependent variables when assessed by the Shapiro-Wilk test $(p<.05)$; however, an inspection of the Q-Q plots revealed only a slight positive skew in the data. Due to the robustness of the parametric test used, it was decided to proceed with the analysis without transforming the data. The subsequent analyses revealed homogeneity of variances, as assessed by Levene's test ( $p>$ .05 ) and homogeneity of covariance, as 
assessed by Box's test $(p>.05)$ for all dependent variables. Any outliers in the data were dealt with using winsorization.

The 10 observed behaviours of interest were analysed using a 2 (expectancy vs control) $\times 2$ (neutral questions vs informationgathering questions) mixed-design ANOVA, where expectancy is the between-subjects factor and question type is the within-subjects factor. The analysis demonstrates that there are main effects of expectancy on blink frequency, $F(1,49)=6.55, p=.01, \eta^{2}=.12$, with the targets in the expectancy group $(M=1.25, S D=0.48)$ blinking less frequently than the targets in the control group $(M=1.64, S D=0.72)$. There is also a main effect of expectancy on response length, $F(1$, $49)=12.47, p=.001, \eta^{2}=.20$, as the targets in the expectancy group $(M=39.6$, $S D=19.5)$ gave shorter answers than the targets in the control group $(M=57.3$, $S D=23.0)$. There is also a main effect of expectancy on smiling behaviour, $F(1$, 49) $=4.96, p=.03, \eta^{2}=.09$, as the targets in the expectancy group $(M=0.36, S D=0.19)$ smiled less than the targets in the control group $(M=0.27, S D=0.17)$. Main effects of expectancy were also found for serious affect, $F(1,49)=4.76, p=.03, \eta^{2}=.09$, with the targets in the expectancy group exhibiting more instances of serious expression $(M=0.99, S D=0.12)$ than the targets in the control group $(M=0.99, \quad S D=0.12)$. Furthermore, a main effect of question type was found for gesturing behaviour (illustrators), $F(1,49)=4.53, p=.04, \eta^{2}=.09$, with the targets in both groups using less illustrators (gestures) in the information-gathering phase $(M=0.94, S D=0.47)$ than in the neutral questioning phase $(M=1.06, S D=0.37)$.

There is a small interaction effect of expectancy and question type on speech disturbances, $F(1,49)=4.86, p=.03, \eta^{2}=.09$; however, it is not in the hypothesized direction. The targets in the control group uttered more speech disturbances in the informationgathering phase of the interview $(M=1.11$,
$S D=0.44)$ than during the neutral questioning phase $(M=0.77, S D=0.37)$. It was suspected that this interaction effect might be an artefact of the differences in response length - that is, the control group spoke more, and thus had the opportunity to use more filler words and pauses. To test this, speech disturbances were reanalysed as a proportion of response duration. The interaction effect of question type and expectancy disappeared; however, main effects of expectancy emerged in the hypothesized direction, $F(1,49)=5.08, p=.03, \eta^{2}=$ .10 , with the expectancy targets demonstrating more speech disturbances $(M=0.24$, $S D=0.01) \quad$ than the control targets $(M=0.14, S D=0.01)$.

No significant main effect of expectancy was found for laughter, $F(1,49)=1.91, p=$ $.173, \eta^{2}=.04$; however, a small interaction effect was found between groups and question type, $F(1,49)=4.37, p=.04, \eta^{2}=.08$. This is due to the targets exhibiting more laughter in the information-gathering phase of the interview $(M=0.10, S D=0.11)$ than the neutral phase $(M=0.14, S D=0.14), p=.03, \eta^{2}=$ .09. However, the control targets drove this difference as they displayed more laughter $(M=0.18, S D=0.20)$ in the informationgathering phase than the expectancy targets $(M=0.10, S D=0.19), p=.05, \eta^{2}=.08$. For the remaining behaviours of interest, no significant main effects were found for eye closures, $F(1,49)=0.61, p=.44$, gaze aversion, $F(1,49)=1.58, p=.22$, or manipulations, $F(1,49)=0.22, p=.64$.

\section{Discussion}

The current study manipulated an expectancy effect in two groups of targets (those exposed to an expectancy and a control group) to examine how their behaviour might differ and change over the course of a non-accusatory interview that used information-gathering questions. The key findings in this study provide evidence that information-gathering questions do not seem to exacerbate expectancy 
effects; however, the presence of expectancy effects can be observed in certain interviewee behaviour over the course of the interview.

\section{The effects of information-gathering questions}

Information-gathering questions were tested against the effects of expectancy by inducing stereotype activation in half of the targets. It was predicted that the resulting expectancy effect, paired with the more investigative style of the questions, would amplify the behaviours indicative of increased cognitive load. Contrary to the hypothesis, the present study suggests that information-gathering questions do not significantly increase the cognitive load that accompanies an existing expectancy effect. That is, unlike guilt-presumptive interview questions, information-gathering questions do not seem to create an expectancy effect on their own and in the absence of other interview tactics (Hill et al., 2008). Although both groups gestured less in the informationgathering phase of the interview, this reduced movement was likely due to only a slight increase in load. That is, the increased cognitive demands were not great enough to influence the other behaviours of interest. While this finding is promising, further research investigating cognitive load in a more highstakes interview setting needs to be conducted.

There is also some evidence that the prime activation may have caused feelings of nervousness in the targets (i.e. once the targets had been told that their results were anomalous and that they needed to answer some additional questions). Nervousness and cognitive load can be present at the same time; however, they often have opposite effects on behaviour. For example, nervous people tend to fidget more and use more manipulators (self-touch), whereas people who are cognitively taxed generally become more still. Therefore, only the effects that are having the greatest influence on behaviour are generally seen (Vytal, Cornwell, Arkin, \& Grillon, 2012). In the present study, it is possible that since the levels of nervousness and cognitive load were not extremely high, some behaviours for both increased mental load and nervousness were observable. For example, the control targets reported more symptoms of nervousness after the interview and exhibited more laughter during the information-gathering phase of the interview (Kasl \& Mahl, 1965). Because the targets who laughed were not conveying humorous information, it was determined that this laughter was used to relieve tension and appear non-threatening (Nelson, 2008).

\section{The effects of expectancy}

The findings in the present study demonstrate the ease with which an expectancy effect can be induced in a target. There are observable differences in the behaviour of the targets who experienced the expectancy effects compared to those in the control group. This finding lends support to the literature that cautions law-enforcement officers, and other legal personnel, against making important decisions based on their visual perceptions of a suspect or interviewee (Vrij, 2008). In the present study there are significant differences between the two groups for blinking, response length, speech disturbances, smiling and serious expression. When behaviour generally associated with increased cognitive load was examined, it was found that the frequency of blinking was decreased for the targets in the expectancy group, which is indicative of the increased mental load that accompanies an expectancy effect (Holland \& Tarlow, 1972; Rosenfield, Jahan, Nunez, \& Chan, 2015). This finding shows that merely planting the negative information was enough to increase the cognitive load and subsequently influence behaviour. Similar findings are reported in other studies, supporting the notion $\rightarrow \rightarrow$ $\rightarrow$ that suggested expectancy effects can be primed and activated automatically with contextual cues (Bargh et al., 1996; Chen \& Bargh, 1997; Leslie et al., 2015). Contrary to expectations, increased eye closure and gaze aversion were not observed in the targets who 
were exposed to the expectancy. Closing one's eyes and breaking eye contact are tactics used by persons experiencing high amounts of mental load in order to reduce external visual stimulus (Doherty-Sneddon and Phelps, 2005; Vredeveldt et al., 2011).

The targets who experienced the expectancy also gave significantly shorter responses across both phases of the interview and demonstrated increased speech disturbances. Short and vague responses are often viewed as an indicator of being uncooperative and evasive (Mann et al., 2008). The targets in the present study had no reason to be ambiguous or unhelpful in their replies. It is possible that these targets did not want to say too much in fear of being perceived as dishonest and thus fulfilling the expectancy about their honesty. It is also reasonable to assume that the increased mental load experienced with the expectancy effect simply made shorter responses easier to deliver. It was anticipated that the targets in the expectancy group would exhibit more speech disturbances ('ums', 'ahhs', etc.) and pauses in their speech. It was assumed that the increased mental load associated with the expectancy effect would cause the targets in the expectancy group to use pauses and speech disturbances in order to collect their thoughts before responding, which was shown to be the case.

Three behaviours were also coded that could potentially provide some insight into demeanour (i.e. smiling, laughing and serious facial expression). Significant behavioural differences between groups and across question types were observed for these variables. The targets in the expectancy group smiled less and maintained more serious facial expressions throughout the questioning, despite reporting a positive mood that was consistent with the targets in the control group. It is likely that the change in demeanour during the information-gathering questions was due to the increased mental load experienced when the targets were informed that there was a potential problem with their task results. This suggests that when the targets were told of the improbability of their results, the situation was perceived as more serious. Note that the targets in both groups reported the informationgathering questions as more accusatory than the neutral questions. The scores for the information-gathering questions do not exceed the mid-point for the rating scale and thus the questions were not scored as overtly accusatory. However, this finding may be an indication of the targets' nervousness during this phase of the interview.

\section{Limitations and future research}

The targets in the present study were all persons telling the truth in a safe and non-threatening environment with a friendly interviewer. However, the presence of an expectancy effect about group membership and honesty was enough to significantly decrease the length of response, eye blinks and smiling while increasing speech disturbances and serious affect. There are clearly some limitations in the present study that need to be addressed in order to fully understand the implications of expectancy effects on investigative interviews. The findings presented herein have been tested in an academic setting in an attempt to extrapolate to a legal context. However, it cannot be concluded that the phenomenon of expectancy effects is a frequent occurrence during investigative interviews, nor can it be concluded that this finding will transfer to real-world situations. However, it has been demonstrated that expectancy effects are potentially another avenue to increased cognitive load in an already cognitively taxing situation. Further research is needed to determine how a non-racially-motivated stereotype may affect targets in a higherpressure, high-stakes interview setting.

Another limitation is that the informationgathering phase of the interview does not realistically reflect a real-world investigative interview using information-gathering techniques. The aim was to choose questions that would incorporate free recall (see Question 6 in Table 2) and encourage more details about 
what went on in the room. The remaining questions are specific and focused on information that could be helpful in a real investigation. Because it was necessary to control for consistency with each target, the interviewer was directed to stick to a script; therefore, prompts, clarifying questions and follow-up questions were not used as they would be in a real investigation. Future research is needed to explore how the altered behaviour of targets, due to increased mental load and expectancy effects, may influence subsequent behaviours in perceivers during investigative interviews in real-world settings.

\section{Conclusion}

When the findings of this study are applied to the investigative interview, important insights emerge. Previous research has demonstrated the effects of cognitive load during mentally taxing tasks and high-stakes investigative interviews. In the present study, similar effects were elicited during a non-accusatory, lowstakes interview about a non-criminal event by using exposure to a false belief about group membership. Identifying how these effects translate into verbal and non-verbal behaviour during an investigative interview can help with understanding how this behaviour can potentially influence the outcome of the interview. Despite the extensive evidence in the literature, some law-enforcement officers still rely on observable behaviours to make decisions regarding the veracity and guilt of interviewees (see Vrij, 2008). The present study illustrates the erroneous nature of such judgements, and highlights why legal decision-makers need to be cognisant of how expectations may influence some of the behaviour they observe.

\section{Acknowledgements}

The findings from this article were previously presented at the European Association of Psychology and Law Conference, Mechelen, Belgium, 2017.

\section{Ethical standards}

\section{Declaration of conflicts of interest}

Nicole M. Adams-Quackenbush has declared no conflicts of interest.

Robert Horselenberg has declared no conflicts of interest.

Josephine Hubert has declared no conflicts of interest.

Aldert Vrij has declared no conflicts of interest.

Peter van Koppen has declared no conflicts of interest.

\section{Ethical approval}

All procedures performed in studies involving human participants were in accordance with the ethical standards of the Ethical Committee for Psychology at the participating university and comply with Standard 8 of the Ethical Principles and Code of Conduct outlined by the American Psychological Association (2010).

\section{Disclosure statement}

The authors declare that there are no potential conflicts of interest with respect to the research, authorship, and/or publication of this article.

\section{Informed consent}

Informed consent was obtained from all individual participants included in the study.

\section{Funding}

This researchwork wais supported by a fellowship awarded from Tthe House of Legal Psychology [grant no. FPA 2013-0036] and [grant no. SGA 2015-1610].

\section{ORCID}

Nicole M. Adams-Quackenbush (D) http://orcid.org/0000-0003-2598-5654 


\section{References}

American Psychological Association (2010). Ethical Principles of Psychologists and Code of Conduct. Retrieved from http://www.apa. org/ethics/code/

Areh, I., Walsh, D., \& Bull, R. (2016). Police interrogation practice in Slovenia. Psychology, Crime \& Law, 22, 405-419. doi:10.1080/1068616X.2015.1114113

Bargh, J. A., Chen, M., \& Burrows, L. (1996). Automaticity of social behavior: Direct effects of trait construct and stereotype activation on action. Journal of Personality and Social Psychology, 71, 230-244. doi: 10.1037/0022-3514.71.2.230

Barrouillet, P., bernardin, S., Portrat, S., Vergauwe, E., \& Camos, V. (2007). Time and cognitive load in working memory. Journal of Experimental Psychology, 33, 570-585. doi:10.1037/0278-7393.33.3.570

Berggren, N., Richards, A., Taylor, J., \& Derakshan, N. (2013). Affective attention under cognitive load: Reduced emotional biases but emergent anxiety-related costs to inhibitory control. Frontiers in Human Neuroscience, 7, 232-238. doi:10.3389/ fnhum.2013.00188

Chen, M., \& Bargh, J. A. (1997). Nonconscious behavioral confirmation processes: The selffulfilling consequences of automatic stereotype activation. Journal of Experimental Social Psychology, 33, 541-560. doi: 10.1006/jesp.1997.1329

Clarke, C., \& Milne, R. (2001). National evaluation of the PEACE investigative interviewing course [Report No. PRAS/149]. London: Home Office.

Croizet, J. C., Despres, G., Gauzins, M. E., Huget, P., Leyens, J. P., \& Load, A. (2004). Stereotype threat undermines intellectual performance by triggering a disruptive mental load. Personality and Social Psychology Bulletin, 30, 721-731. doi:10.1177/ 0146167204263961

De Paulo, B. M., Lindsay, J. J., Malone, B. E., Muhlenbruck, L., Charlton, K., \& Cooper, H. (2003). Cues to deception. Psychological Bulletin, 129, 74-118. doi:10.1037/00332909.129.1.74

Doherty-Sneddon, G., \& Phelps, F. G. (2005). Gaze aversion: A response to cognitive or social difficulty? Memory \& Cognition, 33(4), 727-733. doi:10.3758/BF03195338

Engle, R. W. (2002). Working memory capacity as executive attention. Current Directions is Psychological Science, 11, 19-23. doi: 10.1111/1467-8721.00160
Fazio, R. H., Effrein, E. A., \& Falender, V. J. (1981). Self-perceptions following social interaction. Journal of Personality and Social Psychology, 41, 232-242.

Global Research Deception Team. (2006). A world of lies. Journal of Cross-Cultural Psychology, 37, 60-74. doi:10.1177/00220 22105282295

Gombos, V. A. (2006). The cognition of deception: The role of executive processes in producing lies. Genetic, Social and General Psychology Monographs, 132, 197-214. doi: 10.3200/MONO.132.3.197-214

Gudjonsson, G. H. (2003). The psychology of interrogations and confessions: A handbook. West Sussex, England: John Wiley \& Sons, Ltd.

Hayes, A. F., \& Krippendorff, K. (2007). Answering the call for a standard reliability measure for coding data. Communication Methods and Measures, 1, 77-89. doi: 10.1080/19312450709336664

Hill, C., Memon, A., \& McGeorge, P. (2008). The role of confirmation bias in suspect interviews: A systematic evaluation. Legal and Criminological Psychology, 13, 357-371. doi:10.1348/135532507X238682

Holland, M. K., \& Tarlow, G. (1972). Blinking and mental load. Psychological Reports, 31, 119-127. doi:10.2466/pro.1972.31.1.119

Inzlicht, M., Tullett, A. M., \& Legault, L. (2011). Lingering effects: Stereotype threat hurts more than you think. Social Issues and Policy Review, 5, 227-256. doi:10.1111/ j.1751-2409.2011.01031.x

Kasl, S. V., \& Mahl, G. F. (1965). The relationship of disturbances and hesitations in spontaneous speech to anxiety. Journal of Personality and Social Psychology, 5, 425-433. Retrieved from https://www.ncbi. nlm.nih.gov/pubmed/14328758

Kassin, S. M. (2005). On the psychology of confessions: Does innocence put innocents at risk? American Psychologist, 60, 215-228. doi:10.1037/0003-066X.60.3.215

Kassin, S. M., Drizin, S. A., Grisso, T., Gudjonsson, G. H., Leo, R. A., Redlich, A. D. (2009). Police-induced confessions: Risk factors and recommendations. Law and Human Behavior, 34, 3-38. doi:10.1007/ s10979-009-9188-6

Kassin, S. M., Goldstein, C. C., \& Savitsky, K. (2003). Behavioural confirmation in the interrogation room: On the dangers of presuming guilt. Law and Human Behavior, 27, 187-203. doi:10.1023/A:1022599230598 
Kassin, S. M., Leo, R. A., Meissner, C. A., Richman, K. D., Colwell, L. H., Leach, A. M., \& La Fon, D. (2007). Police interviewing and interrogation: A self-report survey of police practices and beliefs. Law and Human Behavior, 31, 381-400. doi:10.1007/ s10979-006-9073-5

Keller, J. (2007). Stereotype threat in classroom settings: The interactive effect of domain identification, task difficulty and stereotype threat on female students' math performance. British Journal of Educational Psychology, 77, 323-338. doi:10.1348/ 000709906X113662

Lamont, R. A., Swift, H. J., \& Abrams, D. (2015). A review and meta-analysis of agebased stereotype threat: Negative stereotypes, not facts, do the damage. Psychology and Aging, 30, 180-193. doi:10.1037/a0038586

Leal, S., \& Vrij, A. (2010). The occurrence of eye blinks during a guilty knowledge test. Psychology, Crime and Law, 16, 349-357. doi:10.1080/10683160902776843

Leo, R. A. (2009). False confessions: Causes, consequences, and implications. Journal of the American Academy of Psychiatry and the Law, 37, 332-343.

Leslie, S. J., Cimpian, A., Meyer, M., \& Freeland, E. (2015). Expectations of brilliance underlie gender distributions across academic disciplines. Science, 347, 262-265. doi:10.1126/science. 1261375

Mann, S., Vrij, A., \& Bull, R. (2002). Suspects, lies, and videotape: An analysis of authentic high-stake liars. Law and Human Behavior, 26, 365-376. doi:10.1023/A:1015332606791

Mann, S., Vrij, A., \& Bull, R. (2004). Detecting true lies: Police officers' ability to detect suspect's lies. Journal of Applied Psychology, 89, 137-149. doi:10.1037/00219010.89.1.137

Mann, S., Vrij, A., Fisher, R. P., \& Robinson, M. (2008). See no lies, hear no lies: Differences in discrimination accuracy and response bias when watching or listening to police suspect interviews. Applied Cognitive Psychology, 22, 1062-1071. Doi:10.1002/ acp. 1406

Meissner, C. A., Redlich, A. D., Bhatt, S., \& Brandon, S. (2012). Interview and interrogation methods and their effects on true and false confessions. Campbell Systematic Reviews, 13, 1-49. doi:10.4073/csr.2012.13

Merton, R. K. (1948). The self-fulfilling prophecy. The Antioch Review, 8, 193-210. Retrieved from http:/www.jstor.org/stable/ 4609267
Najdowski, C. J. (2012). Stereotype threat in police encounters: Why African Americans are at risk of being targeted as suspects (Doctoral dissertation), University of Texas at El Paso. Retrieved from http://hdl.handle. net/10027/9525

Narchet, F. M., Meissner, C. A., \& Russano, M. B. (2011). Modeling the influence of investigator bias on the elicitation of true and false confessions. Law and Human Behavior, 35, 452-465. doi:10.1007/s10979010-9257-x

Nelson, J. K. (2008). Laugh and the world laughs with you: An attachment perspective on the meaning of laughter in psychotherapy. Clinical Social Work Journal, 36, 41-49. doi:10.1007/s10615-007-0133-1

Pennington, C. R., Heim, D., Levy, A. R., \& Larkin, D. T. (2016). Twenty years of stereotype threat research. A review of psychological mediators. PLoS ONE, 11, e0146487. doi:10.1371/journal.pone.0146487

Porter, S., \& ten Brinke, L. (2009). Dangerous decisions: A theoretical framework for understanding how judges assess credibility in the courtroom. Legal and Criminological Psychology, 14, 119-134. doi:10.1348/ 135532508 X281520

Powell, M. B., Hughes-Scholes, C. H., \& Sharman, S. J. (2012). Skill in interviewing reduces confirmation bias. Journal of Investigative Psychology and Offender Profiling, 9, 126-134. doi:10.1002/jip.1357

Rassin, E., Eerland, A., \& Kuijpers, I. (2010). Let's find the evidence: An analouge study of confirmation bias and criminal investigations. Journal of Investigative Psychology and Offender Profiling, 7, 231-246. doi: 10.1002/jip.126

Rosenfield, M., Jahan, S., Nunez, K., \& Chan, K. (2015). Cognitive demand, digital screens and blink rate. Computers in Human Behavior, 51, 403-406. doi:10.1016/ j.chb.2015.04.073

Rosenthal, H. E. S., Crisp, R. J., \& Suen, M.-W. (2007). Improving performance expectancies in stereotypic domains: Task relevance and the reduction of stereotype threat. European Journal of Social Psychology, 37, 586-597. doi:10.1002/ejsp.379

Schmader, T., \& Johns, M. (2003). Converging evidence that stereotype threat reduces working memory capacity. Journal of Personality and Social Psychology, 85, 440-452. doi: 10.1037/0022-3514.85.3.440

Schmader, T., Johns, M., \& Forbes, C. (2008). An integrated process model of stereotype 
threat effects on performance. Psychological Review, 11, 336-356. doi:10.1037/0033295X.115.2.336

Schmader, T., Major, B., \& Gramzow, R. H. (2001). Coping with ethnic stereotypes in the academic domain: Perceived injustice and psychological disengagement. Journal of Social Issues, 57, 93-111. doi:10.1111/00224537.00203

Shawyer, A., Milne, B., \& Bull, R. (2009). Investigative interviewing in the UK. In T. Williamson, B. Milne, \& S. Savage (Eds.) International developments in investigative interviewing. London, UK: Routledge.

Silverman, A. M., \& Cohen, G. L. (2014). Stereotypes and stumbling blocks: How coping with stereotype threat affects life outcomes for people with physical disabilities. Personality and Social Psychology Bulletin, 40, 1330-1340. doi:10.1177/01461672145 42800

Snyder, M. \& Haugen, J. A. (1994). Why does behavioral confirmation occur? A functional perspective on the role of the perceiver. Journal of Experimental Social Psychology, 30, 218-246. doi:10.1006/jesp.1994.1011

Snyder, M., \& Stukas, A. A. Jr. (1999). Interpersonal processes: The interplay of cognitive, motivational, and behavioral activities in social interaction. Annual Review of Psychology, 50, 273-303. doi:10.1146/ annurev.psych.50.1.273

Steele, C. M., \& Aronson, J. (1995). Stereotype threat and the intellectual test performance of African Americans. Journal of
Personality and Social Psychology, 69, 797-811. doi:10.1037/0022-3514.69.5.797

Vredeveldt, A., Hitch, G. J., \& Baddeley, A. D. (2011). Eyeclosure helps memory by reducing cognitive load and enhancing visualisation. Memory and Cognition, 39, 1253-1263. doi:10.3758/s13421-011-0098-8

Vrij, A. (2008). Nonverbal dominance versus verbal accuracy in lie detection. Criminal Justice and Behaviour, 35, 1323-1336. doi: $10.1177 / 0093854808321530$

Vrij, A., \& Mann, S., (2001). Telling and detecting lies in a high-stake situation: The case of a convicted murderer. Applied Cognitive Psychology, 15, 187-203. doi:10.1002/10990720(200103/04)15:2<187::AIDACP696 > 3.0.CO:2-A

Vytal, K., Cornwell, B., Arkin, N., \& Grillon, C. (2012). Describing the interplay between anxiety and cognition: From impaired performance under low cognitive load to reduced anxiety under high load. Psychophysiotherapy, 49, 842-852. doi: 10.1111/j.1469-8986.2012.01358.x

Wallen, E., Plass, J. L., \& Brunken, R. (2005). The function of annotations in the comprehension of scientific texts: Cognitive load effects and the impact of verbal ability. Educational Technology Research and Development, 53, 59-71. doi:10.1007/ BF02504798

Wheeler, S. C., \& Petty, R. E. (2001). The effects of stereotype activation on behavior: A review of possible mechanisms. Psychological Bulletin, 127, 797-826. doi: 10.1037/0033-2909.127.6.797 